\title{
Application of computer image analysis software for determining incubation period of cavitation erosion - preliminary results
}

\author{
Mirosław Szala ${ }^{1, *}$ \\ ${ }^{1}$ Lublin University of Technology, Mechanical Engineering Faculty, Department of Materials Engineering, Nadbystrzycka 36, \\ 20-618 Lublin, Poland
}

\begin{abstract}
The paper discusses the application of image analysis software ImagePro Plus and Metllo for assessing cavitation erosion wear. The investigation of cavitation damage is performed on a vibratory test rig in compliance with the ASTM G32 standard using the stationary specimen method. Low-alloy steel grade $34 \mathrm{CrNiMo6}$ is used as the test material. Cavitation wear is evaluated by gravimetric and roughness measurements, microscopic observations and computer image analysis in specified exposure times. The computer image analysis of selected surface areas during a predetermined exposure to cavitation time is performed using images captured with a metallographic microscope. Based on the results of scanning electron and stereoscope microscopic observations, the cavitation worn surfaces are qualitatively described. The relations between surface topography, gravimetric measurements and the microscopic results are discussed. The findings obtained by gravimetric and roughness measurements, image processing and microscopic observations are complementary. The results prove the suitability of image analysis for investigating incubation period of cavitation erosion. The quantification of cavitation erosion damage indicates that the incubation period of cavitation erosion of the tested steel lasts for 20 minutes. The results demonstrate that cavitation-worn surfaces at the initial stage of cavitation erosion can be examined using both ImagePro Plus and Metllo.
\end{abstract}

\section{Introduction}

Cavitation consists in the formation and subsequent implosion of vapour bubbles due to local pressure fluctuations in a liquid. Bubbles start to grow even at an almost constant temperature in the vicinity of a lowpressure region, below the saturated vapour pressure of the liquid. When subjected to higher pressure, the bubbles implode.

In engineering systems, two types of cavitation usually occur: hydrodynamic and vibratory. These phenomena have effect on the performance, service and operation time of different types of fluid machinery such as pump systems [1], propellers [2], processing equipment [3], diesel engines [4] and even rocket engines [5]. Even though, cavitation can be beneficial in engineering as shown in the work [6], where ultrasonic processing of uranium desorption is studied, it also causes serious material damage. Components that undergo cavitation can be negatively affected by the cavitation erosion process, which may ultimately lead to the system's failure. Cavitation erosion consists in surface damage and progressive loss of material from a solid due to the action of bubbles in the liquid that systematically collapse at the surface. It is generally accepted that the impact pressure and shock waves generated by the implosion of cavitation bubbles lead to wear of materials [7-10].

Typical cavitation erosion curves plotted in laboratory conditions are shown in Fig. 1. However, as a survey of the literature [7-13] indicates, different nomenclature of periods and various duration times of erosion progress are used. Generally, the cavitation erosion process of metals can be divided into two characteristic stages of damage, distinguished by the amount of material loss. In one stage, surface layer properties are changed, and in the other stage material removal is started, Fig. 1.

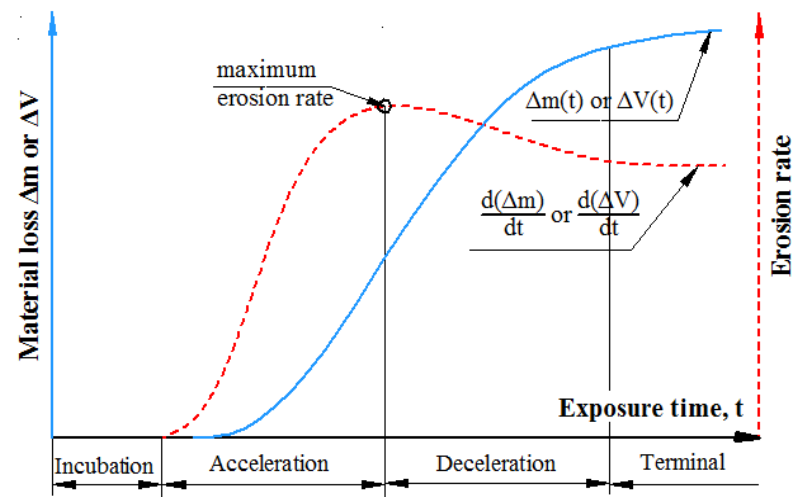

Fig. 1. Cavitation erosion curves with typical period names $(\Delta \mathrm{m}-$ mass loss, $\Delta \mathrm{V}$ - volume loss).

Nevertheless, it is considered that the incubation period of cavitation erosion of metal alloys or overlay coatings can easily be identified [7,10, 13-18]. At this stage of damage, material loss cannot be measured (Fig. 1) and wear can mainly be recognised because of surface deformation. Therefore, the application of topography

\footnotetext{
* Corresponding author: $\underline{\text { m.szala } @ \text { pollub.pl }}$
} 
measurement, microscopic surface investigation and worn surface image analysis are essential to describe qualitatively and quantitatively the incubation period duration and to determine the initial stage of the cavitation erosion process. On the other hand, the literature of the subject does not clearly state which from the above approaches is the most accurate for assessing cavitation wear. The ASTM standard [11] only mentions incubation period duration, but other methods for the evaluation of cavitation wear in incubation period are omitted. For this reason, it seems worthwhile to develop a more efficient method for wear resistance classification based on observations conducted at the initial stage of cavitation erosion.

The incubation period ends when the erosion rate starts to increase, hence the acceleration period begins, Fig. 1. The gravimetric measurement of material loss is a basic method of estimating cavitation erosion of materials. Unfortunately, this method relies on long-term testing in which indicators such as mean depth of erosion and maximum erosion rate of tested materials are determined and compared $[11,16]$. In light of the above, it is vital to devise a method that would rely on the results obtained in the cavitation erosion incubation period (quick testing) and thus help to ensure long-term cavitation erosion resistance. Various method are being developed to shorten test time. In particular, computer image analysis of damaged surface is widely used, hence different approaches are reported [7, 18-20]. A survey of the literature of the problem indicates that despite the fact that MetIlo or ImagePro Plus are widely used in materials science, there are no publications devoted to the application of this software for measuring cavitation erosion resistance. Therefore, this work focuses on this new application for the above software.

The aim of this study is to verify whether the MetIlo and ImagePro Plus image analysis software can be used for evaluating cavitation erosion wear. This is done by comparing the image analysis results with the experimental findings of mass loss, topography measurements and microscopic observations.

\section{Materials and methods}

\subsection{Specimen preparation}

The test material for this study is low-alloy steel grade 34CrNiMo6 in untreated conditions with the following chemical composition: $\mathrm{C}-0.3$ to $0.38 \%$, Si max. $-0.4 \%$, $\mathrm{Mn}-0.5$ to $0.8 \%$, P max. $-0.025 \%$, S max. $-0.035 \%, \mathrm{Cr}$ -1.3 to $1.7 \%$, Mo -0.15 to $0.3 \%$ and $\mathrm{Ni}-1.3$ to $1.7 \%$, according to the EN 10083 standard. The specimen for the cavitation erosion test was machined from a steel rod as a cylinder with a diameter of $25 \mathrm{~mm}$ and a height of $10 \mathrm{~mm}$. The surface of the specimen was described by the following roughness parameters: $\mathrm{Ra}=0.06 \mu \mathrm{m}$ and $\mathrm{Rt}=0.5 \mu \mathrm{m}$.

\subsection{Cavitation erosion test}

The cavitation test was performed using a vibratory apparatus by the stationary specimen method in compliance with the ASTM G-32 [11] test method recommendations. The test was conducted on a test stand schematically shown in Fig. 2 and described in detail in the works [17, 18]. In the present study the distance between the horntip and the specimen's working surface was set to $1 \mathrm{~mm}$ and distilled water with a temperature of $25 \pm 2^{\circ} \mathrm{C}$ was used as a working liquid. The surface of the specimen was examined in exposition times of $5,10,20,40$ and 60 minutes until 120 minutes. The specimen was weighed at each time interval with an accuracy of $0.1 \mathrm{mg}$. A cavitation curve of material mass loss due to cavitation erosion is plotted in Fig. 3.

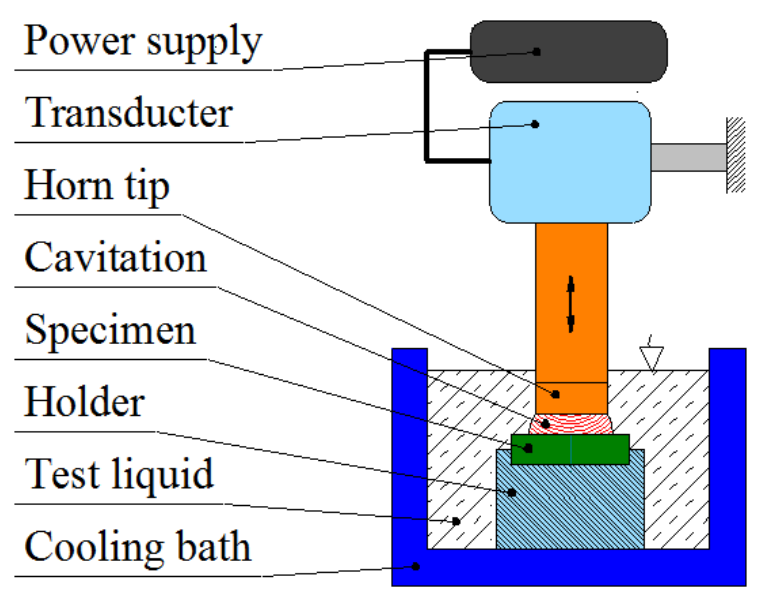

Fig. 2. Schematic design of cavitation erosion test.

Before and during the test, the surface of the specimens was systematically examined and captured in the selected specimen area of $2.21 \mathrm{~mm}^{2}$ with a metallographic optical microscope Nikon MA 200. This was done by the bright field technique. Each time a large image composed of multiple image frames was captured because the size of the examined area exceeded the camera's field of view. The area of surface used for image analysis is shown in Fig. 4, and the development of the area due to cavitation is shown in Fig. 5.

Surface damage caused by cavitation was examined using a stereoscopic microscope Nikon SMZ 1500, Fig. 6. In addition, selected regions of the specimen surface in predetermined exposure times were examined with a scanning electron microscope Phenom ProX (Fig. 7, Fig. 8 and Fig. 9). The scanning electron microscopy (SEM) analysis was conducted using a backscattered electron detector (BSD) with topographical modes (Topo). Two roughness parameters: the arithmetic mean roughness $\mathrm{Ra}$ and the total height of the profile $\mathrm{Rt}$, were measured with a Surtronic $3+$ profilometer, and the results are plotted in Fig. 10.

\subsection{Image analysis}

The computer image analysis was conducted based on the images systematically captured with a metallographic microscope operated in the specified sample area. The surface development due to cavitation was analysed with the MetIlo or ImagePro Plus image analysis software. MetIlo is dedicated to metallographic stereology analysis 
[21] while ImagePro Plus provides state-of-the art imaging and analysis capability for acquiring, enhancing and analysing images [22]. Both programmes enable to detect and measure object attributes such as area, shape characteristic, perimeter, diameter, roundness and aspect ratio, ferret, and many more parameters.

The MetIlo analysis was performed according to the standard metallography procedure described in the works $[21,23,24]$. The tracing and counting of objects by ImagePro Plus was preceded by the assessment of bitmap image (hence the areas affected by cavitation are marked in white). Top and bottom binary thresholds were selected manually. The analysis was based on the images shown in Fig. 11 and Fig. 12. Parameters such as volume fraction, total count, area of each element, perimeter, maximal and minimal feret were measured by both image processing programmes, and the results are given in Fig. 13 and Table 1.

\section{Results and discussion}

The mass loss of 34CrNiMo6 steel due to cavitation was within a range of measuring error until 20 minutes of cavitation exposure (Fig. 3). The total mass loss after 2 hours of cavitation exposure is $15 \mathrm{mg}$, which means that the incubation period of cavitation erosion lasts until 20 minutes.

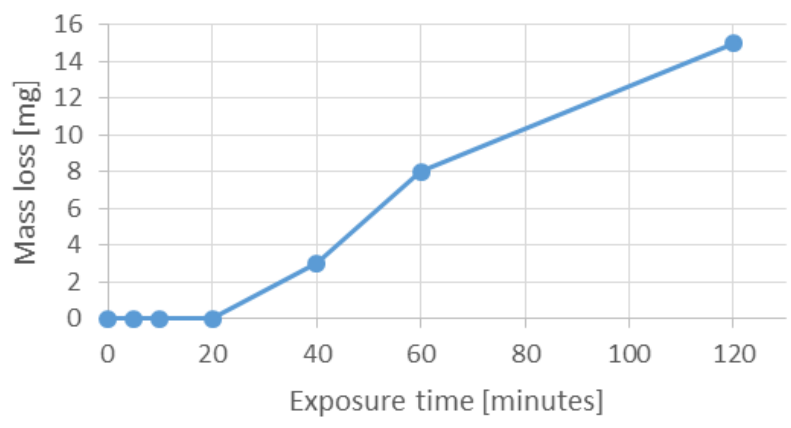

Fig. 3. Cavitation curve of specimen mass loss.

A development of the examined area (Fig. 4) exposed to cavitation is shown in Fig. 5.

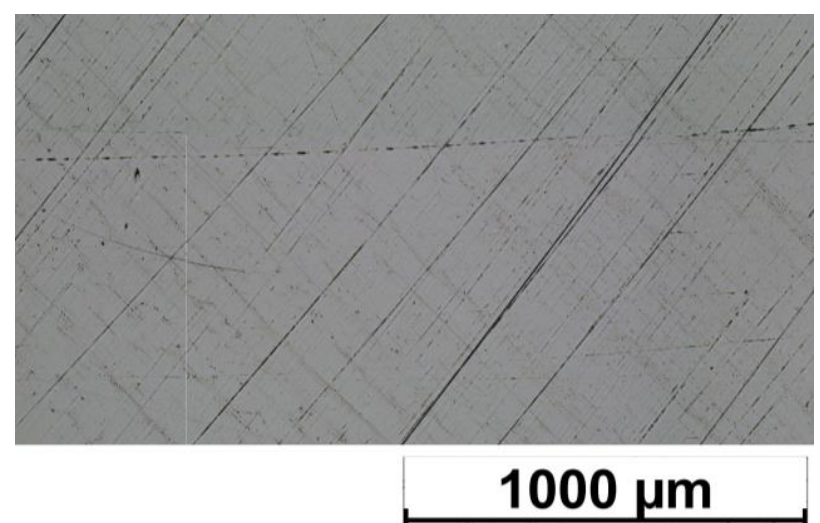

Fig. 4. Surface of 34CrNiMo6 sample before cavitation test input image to analysis.
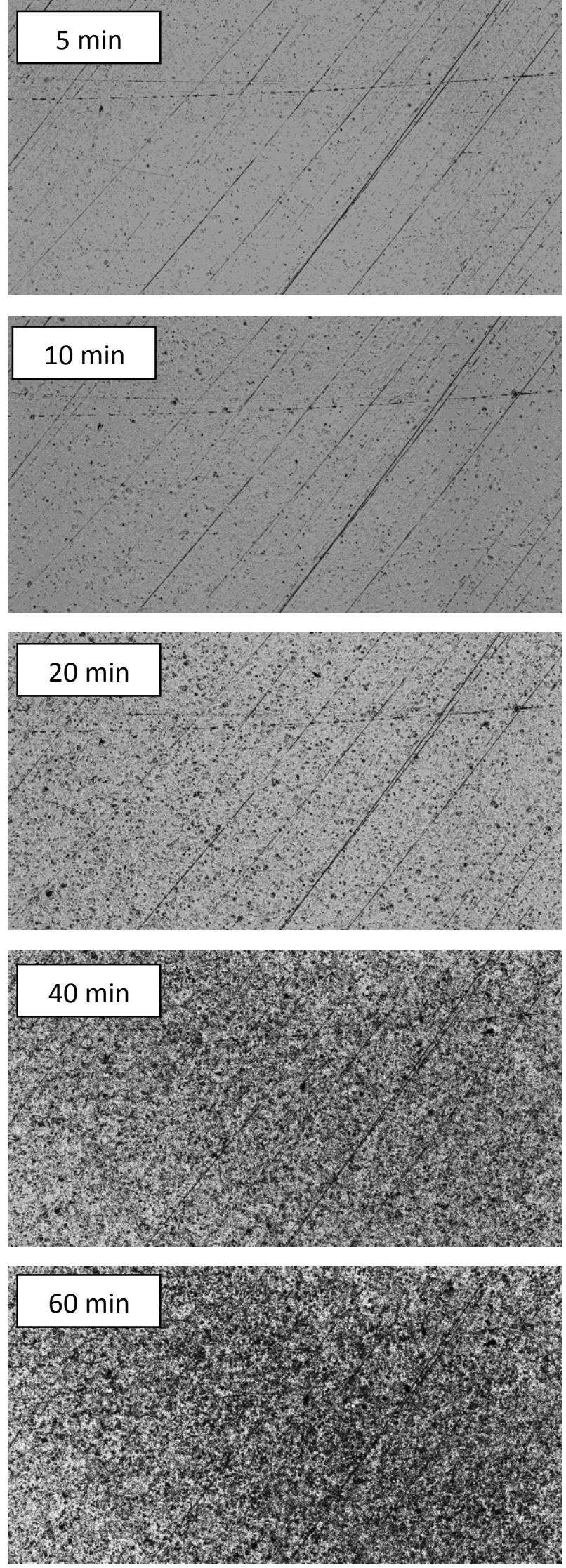

Fig. 5. Cavitation worn surfaces of $34 \mathrm{CrNiMo6}$ steel in different exposure times, metallographic microscopy. 
Changes in the surface are clearly visible when using metallographic optical microscopy (bright light technique). At first, the surface of the specimen under cavitation load begins to deform. Finally, the areas affected by cavitation do not reflect and diffusing light as a result of surface deformation that leads to darker or dark areas in the captured image (Fig. 5).

In contrast, the stereoscope microscope examination visualizes the affected areas as brighter areas. Prior to the test only surface scratches are visible (Fig. 6a), but after 10 minutes of exposure to cavitation one can also notice worn areas (Fig. 6b). The SEM observation of the specimen prepared for the cavitation test confirmed the presence of surface non-uniformities (Fig. 7). Cavitation exerts impact on plastic deformation of the specimen surface (Fig. 8 and Fig. 9)_and leads to an increase in the roughness parameters of the investigated steel (Fig. 10).

The qualitative examination of the worn surface indicates that the incubation period of cavitation erosion involves plastic deformation and the formation and growth of pits. The acceleration period begins after 20 minutes, so the growth of pits and removal of material are visible (Fig. 8 and Fig. 9). Material erosion starts in the vicinity of the scratches, in well-deformed areas and pits as well as in the vicinity to non-uniformities such as inclusions.
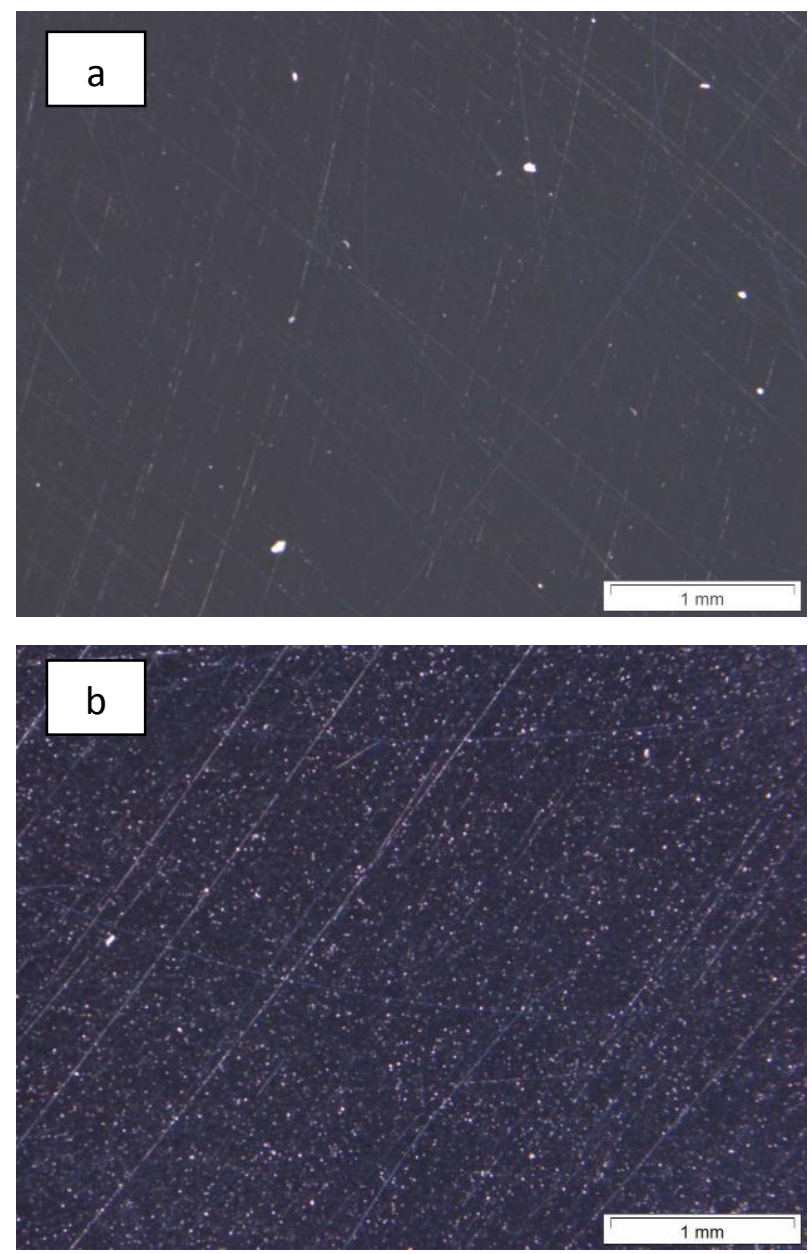

Fig. 6. Surface before cavitation (a) and after 10 minutes (b) of cavitation, stereoscopic microscope.
It can be observed that the roughness parameters $\mathrm{Ra}$ and Rt systematically increase with increasing the exposure time. In comparison with the untreated specimen, the surface roughness of the cavitation-exposed steel specimen almost doubled by the end of the incubation period. There is a correlation between mass loss (Fig. 3) and the Ra parameter, and similar results are reported in the literature $[18,25]$. The quantitative erosion results are in agreement with the SEM results.

Surface roughness increases because of the peaks and valleys in the height direction caused by material erosion. Finally, after 120 minutes, $\mathrm{Ra}$ is $0.23 \mu \mathrm{m}$ and $\mathrm{Rt}$ is $3.05 \mu \mathrm{m}$, which means that image analysis processing is impossible to perform in this particular moment using optical metallographic microscope images captured with the bright field technique. Consequently, the possibility of conducting dark-field examination must be verified
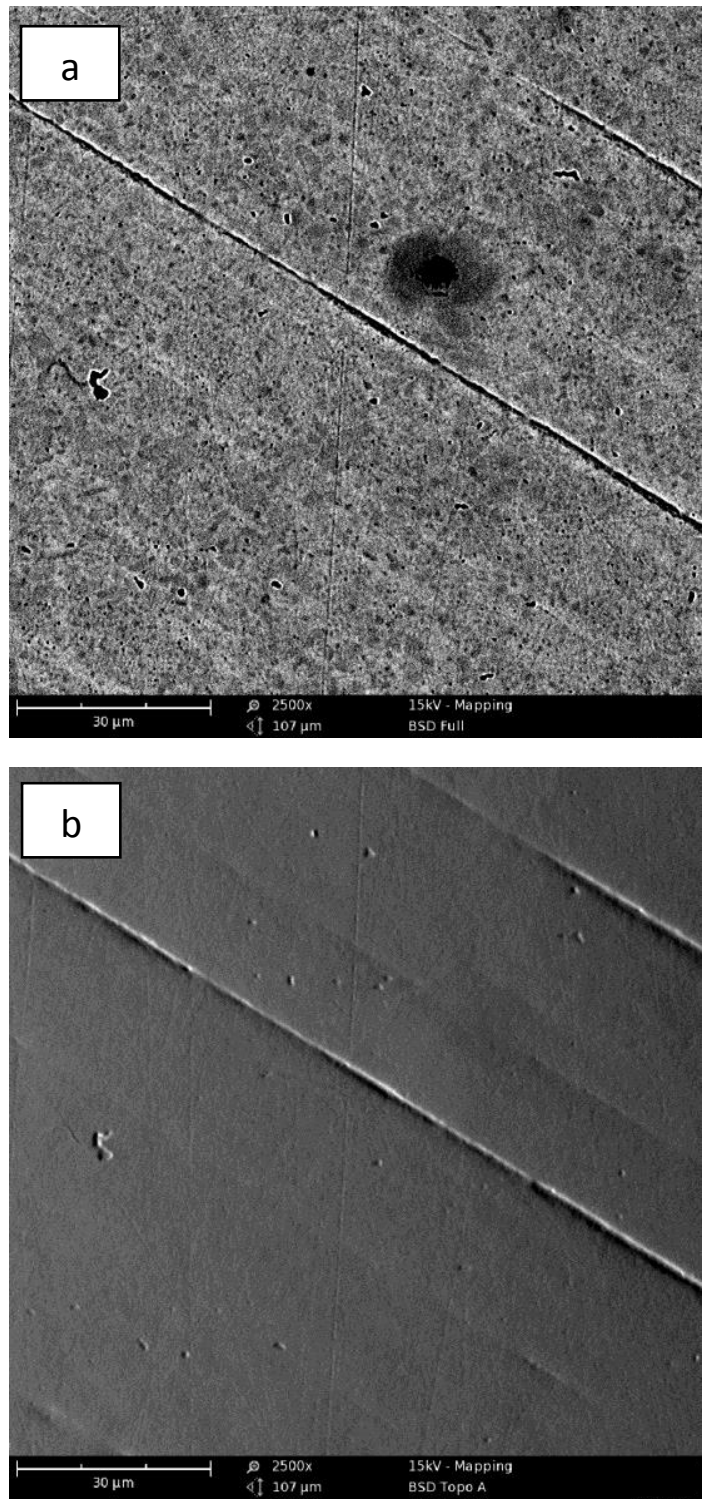

Fig. 7. Selected area of steel surface before cavitation tests, SEM-BSD (a)-and SEM-BSD-Topo (b) modes. 

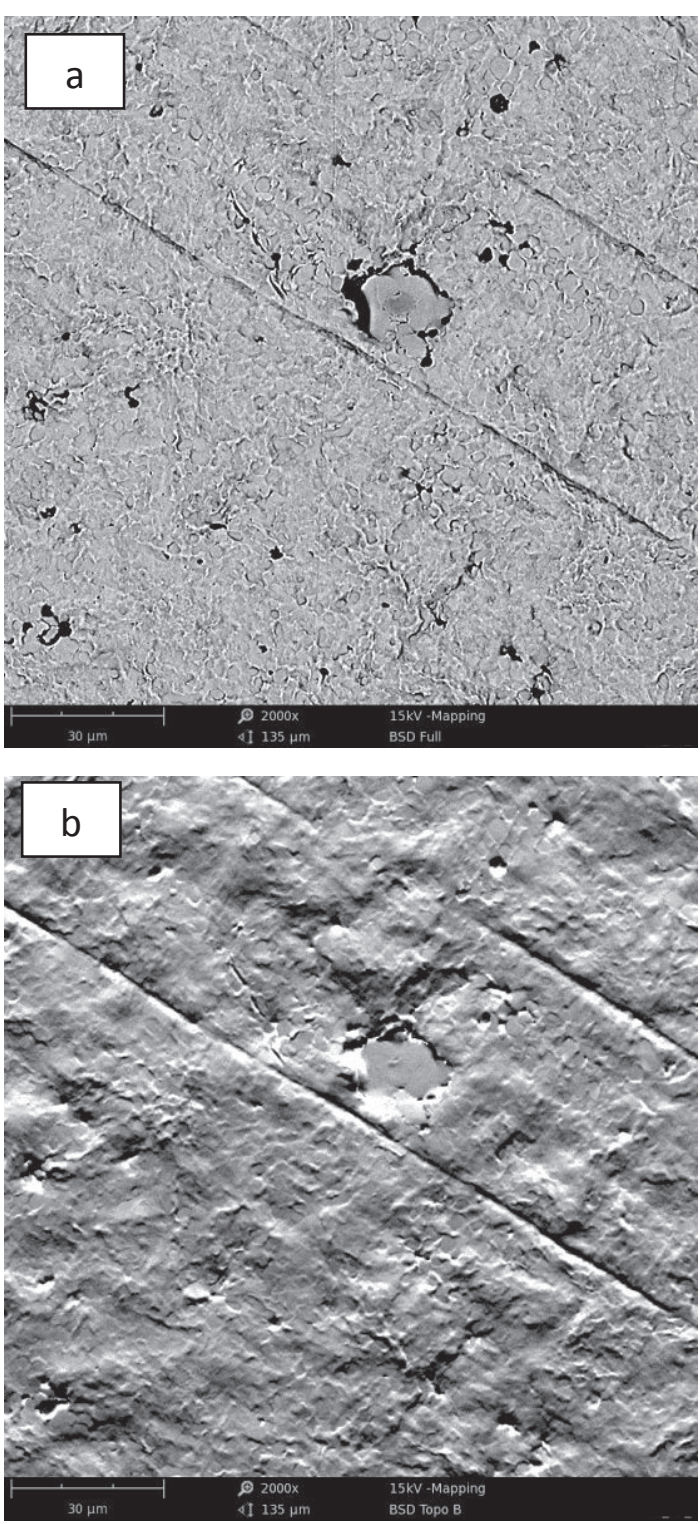

Fig. 8. Selected surface area after 40 minutes of cavitation, SEM-BSD (a), SEM-BSD-Topo (b) modes.

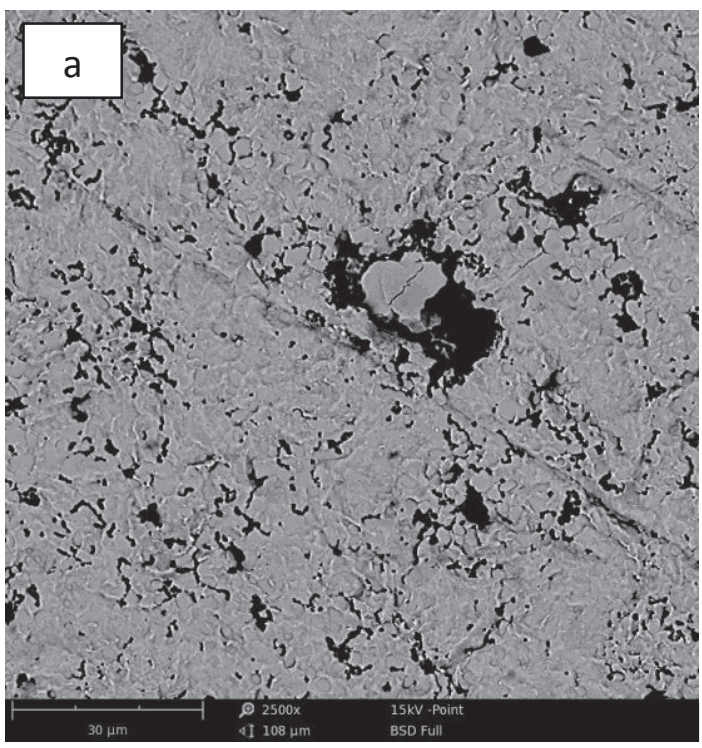

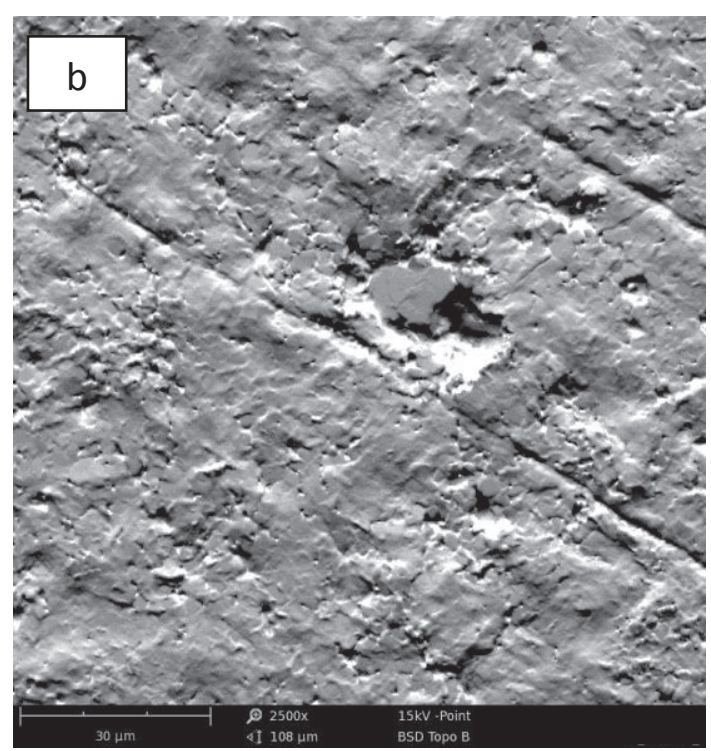

Fig. 9. Selected surface area after 120 minutes of cavitation, SEM-BSD (a), SEM-BSD-Topo (b) modes.

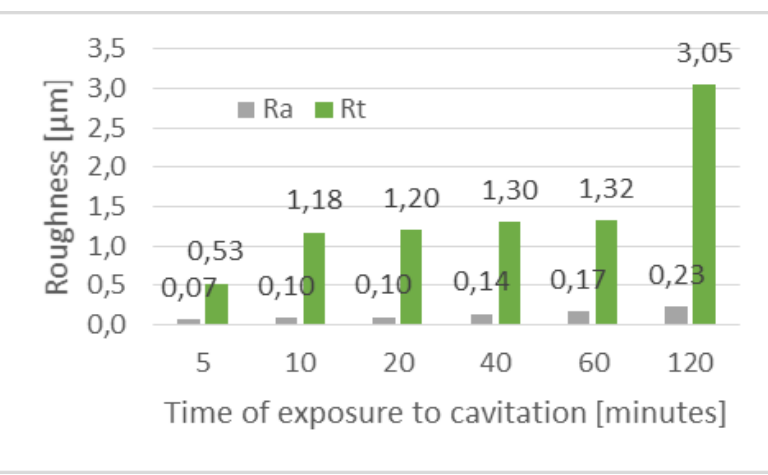

Fig. 10. Results of roughness measurement.

The images generated by computer image analysis are shown in Fig. 11 and Fig. 12, and the numerical results are given in Fig. 13 and Table 1. MetIlo and ImagePro Plus were used to assess wear in the incubation period of cavitation erosion. It can generally be observed that, irrespective of the programme used, every parameter tends to increase, decrease or remain constant depending on the exposure time (Table 1). Once the incubation period of cavitation erosion is over, the trend is reversed. Therefore, it must be statistically investigated whether ImagePro Plus yields more accurate results than MetIlo, and, to this end, more specimens must be statistically examined.

Despite the fact that the results obtained with the two image analysis programmes differ, it is possible to point to the exact moment when the incubation period ends by identifying the moment when parameter tendency starts to change. The end of the incubation period of cavitation erosion can be distinguished by estimating the moment when the investigated parameters change their tendency (from increasing to decreasing, or vice versa). Nevertheless, this problem requires further detailed studies.

The numerical results listed in Table 1 can be useful for describing erosion in terms of quantity and quality. Naturally, one must decide which parameter is the most representative to evaluate cavitation resistance of the material and hence could be used for predicting its 
cavitation wear. The volume fraction of worn areas is not an adequate parameter to determine incubation period duration.

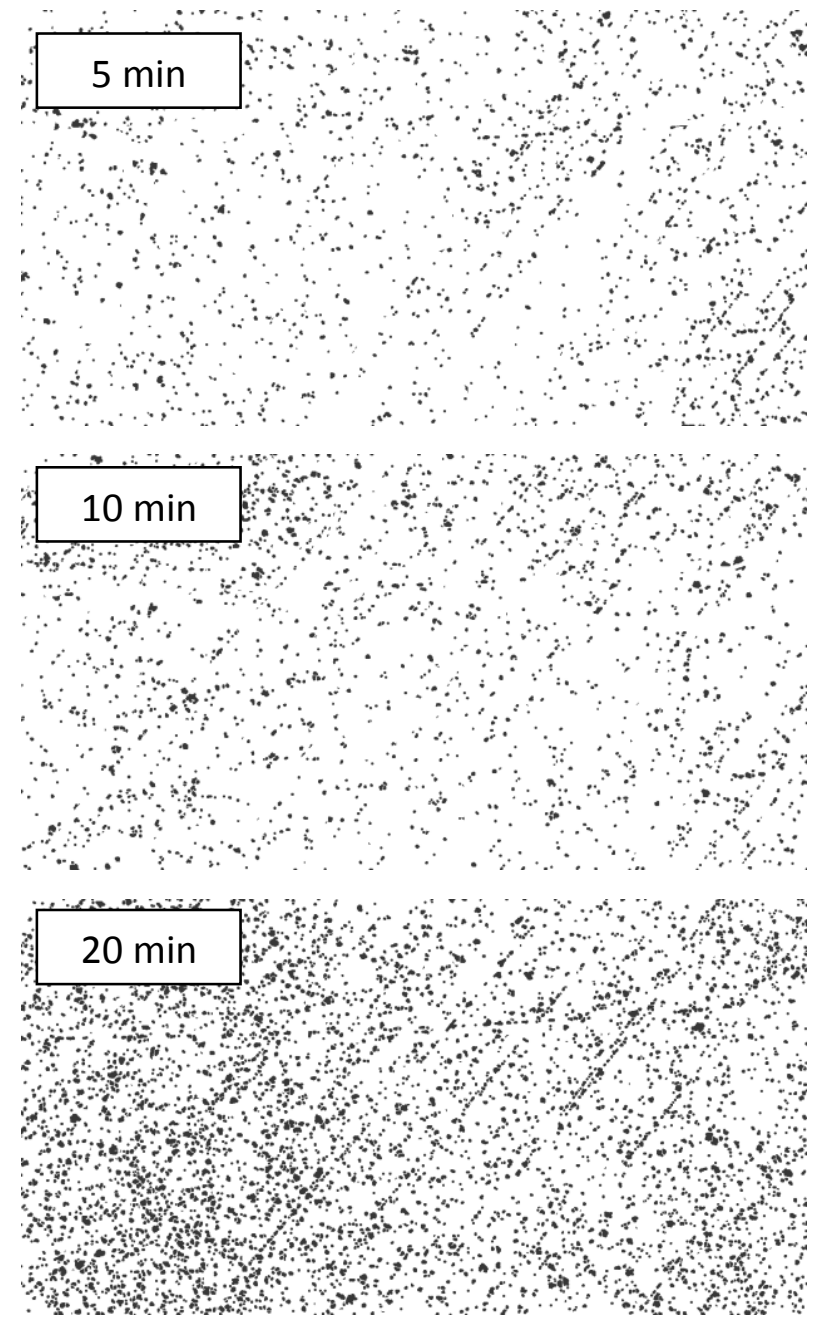

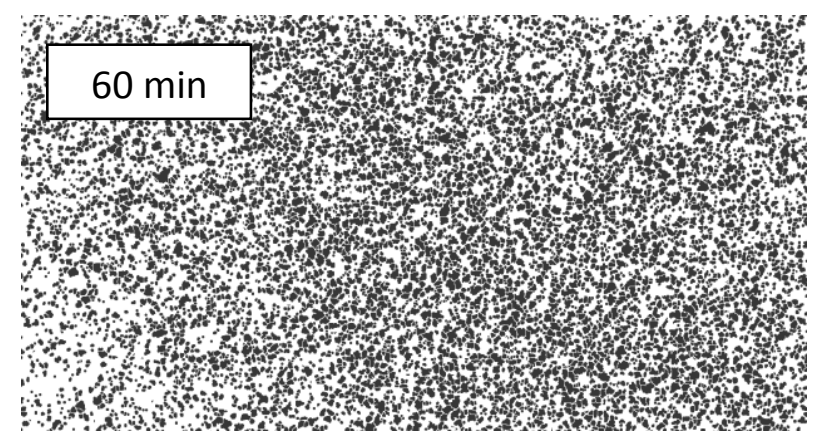

Fig. 11. Images used for image analysis with MetIlo.
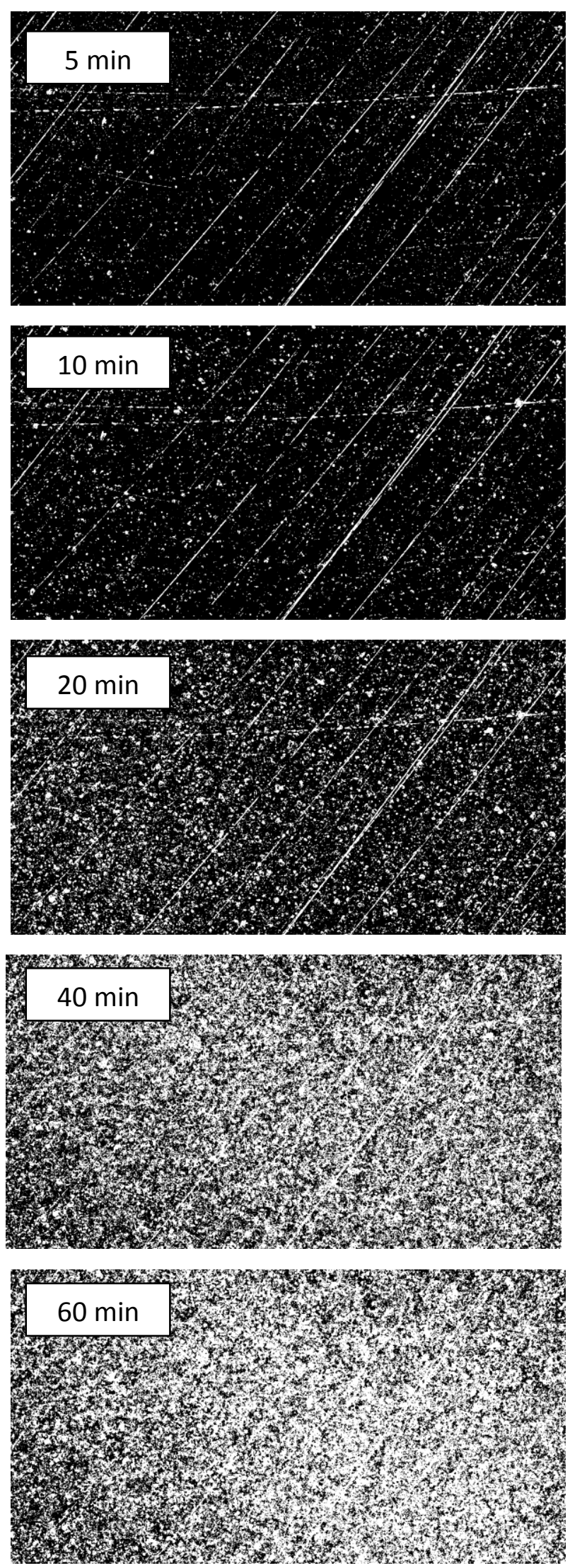

Fig. 12. Images used for image analysis with ImagePro Plus.

It seems that perimeter and ferret could be used to this end because their results indicate that the incubation period of cavitation erosion is 20 minutes, which complies with the results plotted in Fig. 3. In contrast, 
the volume fraction first shows a steady increase, irrespective of the image processing programme. However, after 40 minutes of exposure to cavitation, the MetIlo-simulated volume fraction shows a decreasing tendency, while the ImagePro Plus results show that this parameter is still on the increase (Fig. 13). Examining the volume fraction results it is difficult to determine the exact moment when the acceleration period of cavitation erosion begins.

In addition to the above, statistical methods of results evaluation must be employed, too. It would be a good idea for future studies to compare these results with results obtained with other image analysis software. This would help verify accuracy of the applied procedure.

The scratches observed on the surface of the investigated area do not blur the computer analysis results. This means that the quality of specimen surface roughness preparation was sufficient to determine cavitation wear using computer image analysis.

Table 1. Parameters calculated with MetIlo and ImagePro Plus (mean values) vs cavitation exposure time.

\begin{tabular}{|c|c|c|c|c|c|c|}
\hline & Time [minutes] & 5 & 10 & 20 & 40 & 60 \\
\hline \multirow{7}{*}{ 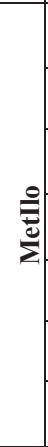 } & $\begin{array}{c}\text { Volume fraction } \\
{[\%]}\end{array}$ & 5.0 & 6.6 & 16.4 & 51.4 & 42.7 \\
\hline & Total count [-] & 1555 & 2115 & 4360 & 8599 & 7233 \\
\hline & $\begin{array}{l}\text { Elements per } \\
\text { area }\left[1 / \mu \mathrm{m}^{2}\right]\end{array}$ & 704 & 958 & 1974 & 3893 & 3275 \\
\hline & $\begin{array}{c}\text { Area of element } \\
{\left[\mu \mathrm{m}^{2}\right]}\end{array}$ & 70.5 & 68.4 & 82.8 & 132.0 & 130.0 \\
\hline & Perimeter $[\mu \mathrm{m}]$ & 25.7 & 24.7 & 27.8 & 37.5 & 37.4 \\
\hline & Feret $\max [\mu \mathrm{m}]$ & 11.0 & 10.7 & 11.7 & 15.3 & 15.3 \\
\hline & $\begin{array}{c}\text { Feret mean } \\
{[\mu \mathrm{m}]}\end{array}$ & 9.7 & 9.5 & 10.5 & 13.2 & 13.3 \\
\hline \multirow{7}{*}{ 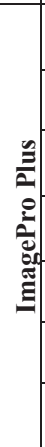 } & $\begin{array}{c}\text { Volume fraction } \\
\mathrm{V}_{\mathrm{V}}[\%]\end{array}$ & 5.7 & 7.3 & 19.6 & 50.4 & 60.2 \\
\hline & Total count [-] & 5152 & 5267 & 10920 & 4562 & 2429 \\
\hline & $\begin{array}{l}\text { Elements per } \\
\text { area }\left[1 / \mu \mathrm{m}^{2}\right]\end{array}$ & 2342 & 2394 & 4964 & 2074 & 1104 \\
\hline & $\begin{array}{c}\text { Area of element } \\
{\left[\mu \mathrm{m}^{2}\right]}\end{array}$ & 24.9 & 31.0 & 40.0 & 246.0 & 551.5 \\
\hline & Perimeter $[\mu \mathrm{m}]$ & 17.3 & 20.5 & 24.9 & 45.5 & 42.8 \\
\hline & Feret $\max [\mu \mathrm{m}]$ & 7.1 & 8.1 & 8.8 & 9.0 & 9.0 \\
\hline & $\begin{array}{l}\text { Feret mean } \\
{[\mu \mathrm{m}]}\end{array}$ & 5.0 & 5.9 & 6.6 & 6.8 & 6.8 \\
\hline
\end{tabular}

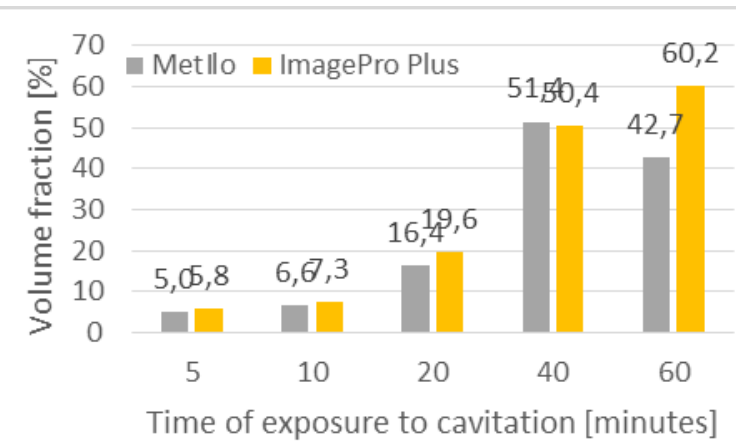

Fig. 13. Comparison of volume fractions of worn area calculated with ImagePro Plus and MetIlo.

\section{Conclusions}

This study reported the preliminary results of study investigating, whether two image processing software programmes: MetIlo and ImagePro Plus, can be used for assessing cavitation erosion wear. The numerical results produced by the above software was then compared with the image analysis results, mass loss calculations, topography measurements and microscopic observations. A new application for these image analysis programmes was proposed.

The results confirm that MetIlo and ImagePro Plus can be effectively used for assessing wear during the incubation period of cavitation erosion.

The duration of incubation period for $34 \mathrm{CrNiMo} 6$ steel was determined using gravimetric, roughness and microscopic measurements and found to be equal to 20 minutes, which is in agreement with the results of computer image analysis. Both image analysis software programmes are suitable for determination of the incubation period duration of cavitation erosion.

The end of the incubation period of cavitation erosion can be determined by computer image analysis based on variations in the investigated parameters. This, however, requires further studies. Unlike parameters, such as perimeter or feret, the volume fraction of worn areas is not adequate to determine incubation period duration.

The results obtained with ImagePro Plus and MatIlo allow for a complementary computer image analysis with gravimetric and roughness measurements and microscopic observations.

Based on the microscopic observations, it has been found that the wear during the incubation period for the investigated steel grade is characterised by plastic deformation and the formation and growth of pits, resulting from the changes in surface roughness. One can observe a systematic increase in the roughness parameters $\mathrm{Ra}$ and $\mathrm{Rt}$ with increasing the exposure time - from $\mathrm{Ra}=0.06 \mu \mathrm{m}$ and $\mathrm{Rt}=0.5 \mu \mathrm{m}$ for the specimen before cavitation, to $\mathrm{Ra}=0.23 \mu \mathrm{m}$ and $\mathrm{Rt}=3.05 \mu \mathrm{m}$ for the specimen after 120 minute-exposure to cavitation.

Future studies will focus on enhancing the computer image analysis procedure and evaluating suitability of its parameters, as well as devising a formula for long-term cavitation resistance of engineering materials based on data collected in the incubation period.

The author wishes to express his gratitude to Bartłomiej Dybowski (Silesian University of Technology, Poland) for carrying out the MetIlo analysis.

\section{References}

1. M. Szala, D. Łukasik, J. Technol. Exploit. Mech. Eng. 2, 40-44 (2016)

2. E. A. Weitendorf, On the History of Propeller Cavitation and Cavitation Tunnels (2001), (available at http://resolver.caltech.edu/CAV2001:sessionB9.001)

3. B. Liu, J. Zhao, J. Qian, ENG FAIL ANAL. 80, 312324 (2017) 
4. M. Simionov, Constanta Maritime University Annals. $15 \quad$ (2011) (available at https://trid.trb.org/view.aspx?id=1124082)

5. M. G. De Giorgi, D. Bello, A. Ficarella, Measurement. 47, 971-981 (2014)

6. E. Panturu, A. Filcenco-Olteanu, A. D. Radu, M. Zlagnean, E3S Web Conf. 18, 01034 (2017)

7. M. Dular, A. Osterman, Wear. 265, 811-820 (2008)

8. J.-P. Franc, J.-M. Michel, Fundamentals of Cavitation (Kluwer Academic Publishers, New York, Boston, Dordrecht, London, Moscow, 2004), vol. 76 of Fluid Mechanics and Its Applications

9. C. E. Brennen, Cavitation and Bubble Dynamics (Oxford University Press, Oxford, 1995)

10. G. Gottardi, M. Tocci, L. Montesano, A. Pola, Wear. 394-395, 1-10 (2018)

11. "ASTM G32-03 Standard Test Method for Cavitation Erosion Using Vibratory Apparatus" (ASTM International, 2003)

12. M. Szkodo, Journal of Materials Processing Technology. 164-165, 1631-1636 (2005)

13. C. Haosheng, L. Jiang, C. Darong, W. Jiadao, Wear. 265, 692-698 (2008)

14. B. Dybowski, M. Szala, T. J. Hejwowski, A. Kiełbus, Sol. St. Phen. 227, 255-258 (2015)
15. S. Hattori, K. Maeda, Wear. 268, 855-862 (2010)

16. J. Steller, Wear. 233-235, 51-64 (1999)

17. M. Szala, T. Hejwowski, I. Lenart, Adv. Sci. Technol. Res. J. 8, 36-42 (2014)

18. M. Szala, Coatings for increasing cavitation wear resistance of machine parts and elements (Lublin University of Technology, Poland, Poland, 2016), Doctoral degree thesis

19. M. Szkodo, Problemy Eksploatacji. 1, 225-231 (2006)

20. A. Osterman, B. Bachert, B. Sirok, M. Dular, Wear. 266, 945-951 (2009)

21. J. Szala, Zastosowanie metod komputerowej analizy obrazu do ilościowej oceny struktury materiatów (Silesian Univeristy of Technology, Poland, 2001), vol. 61 of Zeszyty Naukowe. Hutnictwo

22. Image Processing Software - Image-Pro Plus - Media Cybernetics, (available at http://www.mediacy.com/imageproplus)

23. H. Myalska, B. Dybowski, G. Moskal, Adv. Sci. Technol. Res. J. 11, 220-231 (2017)

24. T. Rzychoń, B. Dybowski, A. Kiełbus, Archives of Metallurgy and Materials. 60, 167-170 (2015)

25. S. A. Romo, J. F. Santa, J. E. Giraldo, A. Toro, Tribology International. 47, 16-24 (2012) 